\title{
Aspectos contemporâneos na joalheria brasileira e o surgimento dos designers empreendedores
}

Contemporary aspects on Brazilian jewelry and the emergence of the designersentrepreneurs

MILAM, Bruna; Mestranda; ESDI-UERJ

bruna.milam@gmail.com

\section{Resumo}

A indústria joalheira vive um momento particular de desafios e de reestruturação, provocado pelas mudanças decorrentes da contemporaneidade. Os designers também sofrem as consequências da crescente individualidade própria do período e, portanto, como forma de adaptação às condições socioculturais enfrentadas, surge no Brasil a figura do designer de joias empreendedor. Este artigo tem como objetivo identificar e analisar de que maneira os aspectos contemporâneos levaram ao aparecimento deste profissional no país. Para isso, faz-se necessário analisar a história do luxo e sua transformação através do tempo, tanto no que se refere às questões produtivas e profissionais, quanto à significância do consumo na sociedade. Por fim, o trabalho atenta para o relevante interesse destes designers nas técnicas artesanais de ourivesaria e, de maneira complementar, também para a influência da chegada de novas tecnologias na joalheria para impulsionamento deste novo perfil de designers de joias no mercado.

Palavras Chave: design de joias; contemporaneidade; empreendedorismo e tecnologias 3D.

\begin{abstract}
The jewelry industry lives a particular moment of challenges and restructuring, caused by the changes of the contemporaneity. The designers also suffer the consequences of the individuality growth that belongs to this period and therefore, as a way of adapting to these sociocultural conditions faced by them, the jewelry designer-entrepreneur emerges in Brazil. This paper identifies and analyzes how the contemporary aspects induced the arise of this professional in the country. For this purpose, it is necessary to analyze the luxury history and its transformation during the time, including productive and professional matter, as well as the significance of the consumption in society. At the end, this work observes the relevant interest from these designers on handcraft jewelry techniques and, additionally, the influence of the arrival of new technologies in jewelry to support this new profile of jewelry designers on the market.
\end{abstract}

Keywords: jewelry design; contemporaneity; entrepreneurship and 3D technologies. 


\section{Introdução - A Joia como artigo de luxo}

A joia é, de maneira geral, identificada como artigo de luxo, devido ao uso de materiais preciosos, metais de alto custo e de pedras raras pela chamada alta joalheria ${ }^{1}$. Porém o campo da joalheria não se limita apenas a este estilo tradicional de joia. Assim como ocorreu com outros artigos de luxo, o conceito de joia se alterou e se fragmentou em diversos nomes e conceitos de ornamentos, principalmente a partir do pensamento contemporâneo. A influência da moda e a crítica à preciosidade tornou o campo mais vasto e complexo do que aparenta.

Porém, ainda que haja em algumas categorias uma distanciação da alta joalheria, parece impossível dissociar a joia da ideia de luxo. E por este motivo, para que se tenha a real compreensão do momento atual da joalheria no Brasil, faz-se necessário analisar a história do luxo e sua transformação através do tempo, e mais precisamente a influência do contexto pósmoderno.

A partir da narrativa histórica e analítica do livro "O Luxo Eterno" de Lipovetsky e Roux, e à luz de autores da sociologia como Harvey, Hall e principalmente Bauman, o artigo propõe-se a identificar e relacionar aspectos do pensamento contemporâneo que levaram ao momento atual da joalheria brasileira, tendo como ênfase o aparecimento da figura do designer empreendedor. Além disto, tomando por base a pesquisa de Ferrara quanto ao surgimento da figura do designer empreendedor no mundo, é possível compreender que a contemporaneidade trouxe mudanças não somente no indivíduo como consumidor, mas também no aspecto do trabalho. Imersos em um contexto de uma sociedade individualizada, munidos de uma formação interdisciplinar e em constante aperfeiçoamento a partir de experimentações, esses novos designers de joias têm a oportunidade de inovar em termos de projeto e abordagem com o mercado, a partir do encontro entre o conhecimento teórico e prático, e através do uso de tecnologias diversas, desde o artesanal até o digital.

A revisão bibliográfica tem como objetivo traçar conexões entre o fenômeno social do designer de joias com atuação empreendedora e o desenvolvimento do pensamento contemporâneo, de maneira a auxiliar o entendimento do panorama atual onde estes profissionais se inserem. A partir do quadro geral, é possível seguir com estudos aprofundados sobre estes profissionais, assim como o proposto na pesquisa de mestrado que vem sendo desenvolvida pela autora. Nesta pesquisa, irá somar-se ainda uma revisão de literatura tendo como tema a história da joalheria no Brasil e outra cujo tema são as tecnologias utilizadas na joalheria. Juntamente com a aplicação de entrevistas que têm como objetivo identificar o impacto das novas tecnologias na motivação destes designers a empreender na joalheria fluminense, espera-se entender de que maneira a difusão de novas tecnologias na joalheria tem influenciado o surgimento de designers de joias empreendedores no Rio de Janeiro.

\section{A História do Luxo e Sua Transformação}

\subsection{Origem e Transformação}

Segundo Lipovetsky (2005, p. 22) a origem do luxo nas sociedades primitivas não começou a partir da fabricação de bens de preço elevado, mas com o espírito de dispêndio. $O$ motivo para o

\footnotetext{
${ }^{1}$ o termo vem da tradução do francês haute joallerie, que surgiu provavelmente em alusão à haute couture, o equivalente a alta-costura em português
} 
gasto excessivo era a dádiva das ofertas cerimoniais, trocas de presentes e distribuição de bens. Para os chefes, mostrar-se generoso através de grandes banquetes e festas tinha o papel de conservar sua condição social ou realçar seu prestígio. No entanto, o luxo tinha valor não só como elemento social, mas também espiritual. A religião estava intrinsecamente ligada ao luxo, no momento em que a oferta ostentatória de presentes e festas era uma maneira de criar uma ligação com espíritos e deuses, e atrair proteção e benevolência. É interessante perceber que dessa forma, o luxo operou em boa parte da história humana como uma maneira de equilibrar a distribuição de riquezas.

Porém foi com o aparecimento dos Estados e a divisão da sociedade em classes que houve a ruptura mais importante da história do luxo, conforme destaca Lipovetsky $(2005$, p. 28). "O luxo não mais coincidiu com os fenômenos de circulação-distribuição-desentesouramento (sic) das riquezas, mas com novas lógicas de acumulação, centralização e hierarquização". Os reis viam-se obrigados a construir templos suntuosos e decorá-los faustosamente, sendo a arquitetura monumental o instrumento mágico que facilita a vida eterna, mas que ao mesmo tempo opera como elemento de diferenciação e de autoafirmação social.

Já com o aparecimento da burguesia, o luxo ganhou força como meio de sustentar a posição social da nobreza tradicional frente à concorrência burguesa, que se utilizava dos signos de riqueza para legitimar sua ascensão social. E se a arte já possuía um elo com o luxo, celebrando forças espirituais em busca de uma eternidade celeste, foi a partir do século XIV, com a Renascença, que a dimensão de eternidade do luxo tornou-se laica. A arte passou a ser usada para eternizar na história a memória de uma pessoa ou de uma família. Paralelamente, a paixão pelas coisas belas e o erotismo dos bens raros, marcou o início do momento moderno e estético do luxo, caracterizado pela individualização e sensualização. Dois fenômenos antagônicos passaram a fazer parte do luxo moderno: as antiguidades e a moda.

E se na Renascença os artistas viviam seu momento de glória, para Lipovetsky (2005), os artesãos eram desconhecidos e viviam em uma situação subalterna. Embora houvesse a fabricação de peças únicas, o trabalho parecia não ser tão valorizado quanto o material utilizado na confecção. Mas a partir do século XVIII, uma série de mudanças culturais ocorridas com o aparecimento do movimento lluminista e com a Revolução Industrial, culminou no movimento modernista no século XX. A Modernidade marca um processo de rupturas com o passado e que, conforme apresenta Harvey (1992, p.21), traz uma conjugação entre opostos: de um lado o efêmero e fugidio e de outro o eterno e imutável. Essa conjugação passa a compor o paradoxo temporal do luxo que se estende até os tempos atuais: a moda sendo o elemento efêmero e a tradição o elemento de eternidade.

Segundo Hall (2006, p.25), a Modernidade traz consigo também uma nova forma de individualismo, do sujeito individual e sua identidade, liberto de apoios estáveis nas tradições e estruturas.

O nascimento do 'indivíduo soberano', entre o Humanismo Renascentista do século XVI e o lluminismo do século XVIII, representou uma ruptura importante com o passado. Alguns argumentam que ele foi o motor que colocou todo o sistema social da "modernidade" em movimento. (HALL, 2006, p.25)

Dentro desse contexto, a situação subalterna e de anonimato do artesão altera-se: nasce o costureiro como um criador livre e independente. "A idade moderna do luxo vê triunfar o costureiro liberto de sua antiga subordinação à cliente e afirma seu novo poder de dirigir a moda". 
(Lipovetsky, 2005, p.43). Houve o surgimento da alta-costura, onde o produto leva o nome de um grande costureiro ou de grandes casas, que mantinham um trabalho artesanal, sob medida e de alta qualidade, seguido pela inserção de novas técnicas de fabricação industrial, que permitiram uma produção em série e celebraram a união entre o artesanato de arte e a indústria. Mas com o avanço industrial surgiu também o chamado "semiluxo", pautado na cópia, com preço mais baixo e tendo como público as classes médias. Segundo Lipovetsky $(2005$, p.45) foi a primeira forma de democratização do luxo, que tinha como suas maiores propagadoras os grandes magazines.

E com os tempos democráticos, quando todos têm acesso ao excesso de signos e a ostentação estética, o luxo mais uma vez se adapta para cumprir seu papel social. A diferenciação passou a ser feita a partir da sobriedade dos trajes e da rejeição à ênfase decorativa: o que Balzac chama de "luxo de simplicidade" (apud LIPOVETSKY, 2005, p.47). Na moda, tal fase do luxo pode ser notada na adoção de trajes pretos masculinos no século XIX e na revolução dos trajes femininos em 1920, tendo como grande ícone a Chanel.

\subsection{Consumo e Luxo Contemporâneo}

As transformações seguintes tornaram o luxo tal como se apresenta hoje. Parece impossível falar sobre o luxo atual sem fazer conexão com o período histórico social, cultural e estético que se sucedeu à Modernidade. Diversos nomes foram cunhados para tal período, a depender do autor a que se refere: pós-modernidade (Harvey e Lyotard), hipermodernidade (Lipovetsky) ou modernidade líquida (Bauman); esses são apenas alguns exemplos. Entende-se aqui, em linhas gerais, que corresponde a uma exacerbação das caraterísticas modernas, influenciado em grande parte pela globalização.

No luxo, temos as operações de fusão e aquisição de grandes casas (agora marcas) e a construção de verdadeiros impérios internacionais. Onde antes víamos uma produção mais parecida com uma manufatura, um casamento perfeito entre a lógica artesanal e a industrial, agora vemos a lógica industrial de produção em série reinando para satisfazer às expectativas e gostos dos clientes. Conforme afirma Lipovetsky, "Depois de cem anos de um ciclo de luxo artístico dominado pelos ateliês da oferta, eis o tempo do luxo-marketing centrado na procura e na lógica do mercado" (2005, p. 50).

Segundo Bauman (2001, p. 37), duas características tornam essa nova modernidade diferente. Primeiramente, o colapso e declínio da ilusão moderna, de que há um telos ${ }^{2}$ alcançável, um estado de perfeição a ser atingido. Complementarmente, a segunda característica diz respeito à desregulamentação e privatização das tarefas e deveres modernizantes, que não pertencem mais ao Estado. Em outras palavras, a fragmentação das tarefas e deveres coletivos. E foi essa última, a característica que mais influenciou o luxo e deu força ao consumismo: o crescimento da individualidade.

Se na Modernidade havia incerteza e insegurança quanto aos meios para se chegar ao objetivo final de sociedade perfeita; na pós-modernidade a incerteza está em não saber os fins (SCHULZE apud BAUMAN, 2001, p.72) e isso causa uma sensação de ansiedade perpétua. E para escapar do fantasma das incertezas e inseguranças do caminho, para Bauman $(2001$, p.96) o consumo aparece como uma espécie de exorcismo, praticado dia após dia: "eles são eficazes e satisfatórios não tanto porque afugentam os fantasmas (o que raramente o fazem), mas pelo

\footnotetext{
${ }^{2}$ palavra de origem grega; significa finalidade, fim, meta, objetivo
} 
próprio fato de serem realizados". Ao mesmo tempo, o consumo tem hoje como maior objetivo a satisfação de desejos e não mais a satisfação de necessidades, portanto muito mais volátil e efêmero, o que alimenta ainda mais esse ciclo vicioso do consumismo. Conforme ilustra Bauman: "A lista de compras não tem fim. Porém por mais longa que seja a lista, a opção de não ir às compras não figura nela" (2001, p. 88). O autor defende que a grande diferença da modernidade sólida para a modernidade líquida é a mudança de uma sociedade de produtores para uma sociedade de consumidores.

O consumo vai além em seu papel de solidificar incertezas da individualidade contemporânea. Ele auxilia em um dos grandes fardos da sociedade atual: a busca de identidade. Para Bauman, "a busca da identidade é a busca incessante de deter ou tornar mais lento o fluxo, de solidificar o fluido, de dar forma ao disforme" (2001, p. 97). E a moda tornou-se a ferramenta perfeita para a expressão de identidade. Ao mesmo tempo que permite uma construção aparentemente consistente, é volátil o suficiente para ser dissolvida e refeita a todo momento, acompanhando a instabilidade intrínseca de nossas identidades.

E foi a partir desta percepção que o luxo evoluiu para o que temos hoje, equilibrando tradição e inovação de forma a satisfazer desejos e auxiliar na construção de identidades.

Nem tradição nem moda, o luxo hoje é hibridação da tradição e da moda, reestruturação do tempo da tradição pelo tempo da moda, reinvenção e reinterpretação do passado pela lógica-moda do presente. (LIPOVETSKY, 2005, p. 83)

E se analisarmos mais a fundo o consumo na sociedade pós-moderna, onde a falta de segurança de longo prazo cria a necessidade de uma satisfação instantânea, é coerente até mesmo questionar o que seria o luxo nos tempos atuais:

A idéia de "luxo" não faz muito sentido, pois a idéia é fazer dos luxos de hoje as necessidades de amanhã, e reduzir a distância entre o "hoje" e o "amanhã" ao mínimo tirar a espera da vontade. Como não há normas para transformar certos desejos em necessidades e para deslegitimar outros desejos como "falsas necessidades"; não há teste para que se possa medir o padrão de "conformidade": (BAUMAN, 2001, p.90)

\section{Designer Empreendedor}

O crescimento da individualidade na sociedade pós-moderna reflete-se não somente nos indivíduos como consumidores, mas também na vida profissional dos mesmos. Segundo Ulrich Beck:

A tendência é o surgimento de formas e condições de existência individualizadas, que compelem as pessoas - para sua própria sobrevivência material - a se tornarem o centro de seu próprio planejamento e condução da vida... De fato, é preciso escolher e mudar a própria identidade social, e assumir os riscos de fazê-lo... O próprio indivíduo se torna a unidade de reprodução do social no mundo da vida. (apud BAUMAN, 2001, p. 155)

É possível ver uma conexão entre esta mudança sociocultural de vida individualizada e o crescimento do fenômeno de autoprodução/autopromoção ${ }^{3}$ na Europa a partir dos anos 90, apontado por Marinella Ferrara em seu artigo para o Strategic Design Research Journal em 2011. Coincidentemente, para alguns autores, um dos acontecimentos que marcam o início da pósmodernidade é datado da mesma época: a queda do muro de Berlim em 1989.

\footnotetext{
${ }^{3}$ tradução livre
} 
Segundo Ferrara, esse fenômeno obteve maior visibilidade durante as semanas de design de Milão, Londres, Bruxelas e Istanbul, além de cidades do norte da Europa. Porém hoje se expandiu pelo mundo, incluindo América Latina e especialmente o Brasil, onde o fenômeno tem caráter de valor social e de inclusão, com características expressivo-simbólicas (2011, p.6). Ainda segundo a autora, isso não significa que esses jovens designers se oponham ao desenho para a indústria e nem tampouco se identifiquem com o movimento Arts and Crafts de William Morris, onde a industrialização é entendida como um inimigo da liberdade criativa. Apenas admite-se a possibilidade de unir a produção industrial com a lógica da peça única, feita por experimentação.

Trata-se de uma transformação na atuação do designer, onde o ato de projetar toma uma concretude maior, já que há uma proatividade do designer para levar o projeto além, como por exemplo, com a construção de protótipos para apresentar ao mercado (empresas, exposições, concursos, etc), "autopromovendo sua identidade como indivíduo ou como um grupo, com seus pensamentos e ideias, os designers promovem a si próprios como artesãos, vendedores de suas próprias criações, e frequentemente são também fotógrafos e vendedores ambulantes." 4 (FERRARA, 2011, p.6)

É apoiado em um conceito de "artesão inteligente" que surge o chamado designer empreendedor (designer-entrepreneur) apresentado por Ferrara, que entende o design autoproduzido como uma forma de resposta à crise do trabalho, enfrentada pelos jovens designers (2011, p.12). Em uma sociedade individualizada, onde não há certezas e tudo aquilo que se colhe depende apenas do esforço individual, sem que haja instituições em que se possa confiar alguma responsabilidade sobre seu destino, é razoável que o designer enquanto indivíduo decida assumir todas as responsabilidades para o sucesso de seu projeto. A assunção de cada vez mais responsabilidades e das mais diversas, a chamada multifuncionalidade, é um fenômeno presente em todo o mercado de trabalho atual. Mas é de esperar que este fenômeno abarque especialmente o campo do design, que é por definição uma atividade estratégica e interdisciplinar.

"Flexibilidade" é o slogan do dia, e quando aplicado ao mercado de trabalho augura um fim do "emprego como o conhecemos": anunciando em seu lugar o advento do trabalho por contratos de curto prazo, ou sem contratos, posições sem cobertura previdenciária, mas com cláusulas "até nova ordem": A vida de trabalho está saturada de incertezas. (BAUMAN, 2001, P.169)

A partir da análise dos métodos empregados pelos designers empreendedores, Ferrara identificou três linhas de pesquisa: artesanato do tipo "faça você mesmo" - aqui identificado como artesanato DIY (do-it-yourself), artesanato tecnológico e artesanato eletrônico ${ }^{5}$.

O artesanato DIY refere-se ao design e produção de peças únicas ou pequena escala de objetos feitos à mão, de custo baixo e materiais simples, que não têm a intenção de serem tão sofisticados quanto os produtos industriais. Por vezes são feitos de rejeitos, sobras ou materiais reciclados e são resultados de pequenas ideias, referências a estilos de vida ou mesmo uma leitura poética do autor. Já o artesanato tecnológico combina as qualidades do trabalho manual com novas tecnologias, "demonstrando que o problema não está em retornar ao feito à mão, mas em

\footnotetext{
${ }^{4}$ tradução livre de: self-promoting its identity as an individual or as a group, with his/her own thoughts and ideas, the designers promote themselves as artisans, producers, graphic communicators, sales agents of their own creations, and are often photographers and traveling salesmen.

${ }^{5}$ tradução livre de: do-it-yourself craft (handcraft-DIY), technological crafts and electronic craft
} 
estar ciente de como o trabalho manual estimula o processo criativo" 6 (FERRARA, 2011, p.9). A terceira linha de pesquisa é o artesanato eletrônico, onde o desenvolvimento do objeto é totalmente digital e se apoia nas novas tecnologias de fabricação digital (também conhecida como prototipagem rápida) para dar vida ao produto. Nesse caso o designer funciona como uma espécie de escultor digital e "combina a atitude tradicional do artesão com experimentos que testam o potencial da informação e das tecnologias digitais" ${ }^{7}$ (FERRARA, 2011, p.10).

E se por um lado, a individualidade pós-moderna atinge o designer de maneira a estimular uma atitude proativa e autônoma, ela atinge também o consumidor, que passa a valorizar mais aspectos individuais e aquilo que torna cada produto único. Além do aumento do desejo de se ter objetos personalizados e exclusivos, feitos especialmente para a pessoa, o interesse pelo indivíduo artesão e/ou criador e seu método de trabalho ganha maiores proporções. Surge uma espécie de empatia, onde o cliente valoriza ainda mais o produto ao conhecer o artista criador, entender seu processo produtivo, identificar as dificuldades do ofício e as habilidades necessárias para tal. Cresce a valorização do trabalho autoral e esta pode ser uma abordagem interessante a ser utilizada pelos designers empreendedores.

\subsection{Designers de Joias Empreendedores no Brasil}

Dentro deste contexto de trabalho contemporâneo, o campo do design de joias também sofreu e vem sofrendo alterações semelhantes. No presente artigo, o foco é analisar de que forma a modernidade e a contemporaneidade influenciaram o mercado de trabalho da joalheria brasileira, no que tange à figura do designer, ao ponto de ver nascer também na joalheria o designer empreendedor.

A partir de meados de 1960, foi possível observar um crescimento de movimentos de joalheria autoral no Brasil, onde se prioriza a expressão individual do autor e cujas peças levam a assinatura do artista ou joalheiro. Dentre estes movimentos, podemos citar como exemplo a joalheria de arte, a nova joalheria e a joalheria contemporânea. A definição de cada um desses movimentos é complicada, uma vez que eles se relacionam entre si e por vezes são apropriações de termos estrangeiros. Aqui vamos nos ater a definições simples a partir da apresentação de características que, de alguma maneira, diferenciam os três movimentos entre si.

Segundo Engracia Costa, os principais nomes da joalheria de arte brasileira vinham das artes plásticas e da arquitetura e tinha como público os apreciadores de arte: "Como obras de arte, as peças dos artistas joalheiros são desenvolvidas sem compromisso com o mercado em maior escala; suas criações são formas de expressão pessoal, independentes e originais" (DAYÉ; CORNEJO; COSTA, 2017, p.241). Já a nova joalheria surgiu inspirada no movimento New Jewelry europeu, e veio com um discurso de contestação e valorização do processo criativo a partir do uso de materiais não nobres e uma estética oposta ao tradicional e belo.

Por outro lado, a joalheria contemporânea, conforme observa Besten (apud MERCALDI, 2016, p.19), é uma joia relativa ao presente, ao "do nosso tempo". Para Mercaldi (2016, p.21), "a joia contemporânea tangencia as fronteiras entre arte, artesanato, moda e design e reflete as condições da atualidade nas quais ela ocorre".

\footnotetext{
${ }^{6}$ tradução livre de: demonstrating that the problem is not returning to a handmade form but being aware of how handcrafting stimulates the creative process.

${ }^{7}$ tradução livre de: combines the traditional handcraft attitude with experiments that test the potential of information and digital technologies.
} 
A partir destas influências, os designers empreendedores aparecem também no campo da joalheria. Embora de cunho autoral e podendo também compreender uma ou mais características destes movimentos, o trabalho de joalheria praticada por estes designers difere dos movimentos anteriormente citados por possuir forte compromisso com o mercado e pela pretensão em ser mais amplamente comercializado, de forma a disputar espaço até mesmo com a joalheria mais tradicional. Assim como o designer empreendedor de Ferrara, assemelha-se a um "artesão inteligente": combina conhecimentos práticos de confecção de joias, obtidos através de cursos técnicos de ourivesaria e joalheria artesanal, com conhecimento de criação e desenvolvimento obtidos através de cursos superiores em Design ou áreas afins.

Estes profissionais possuem preocupação em construir uma identidade de marca própria e concorrem, ainda que indiretamente, com grandes joalherias ao oferecerem peças com design original e/ou personalizado. Por esta última característica, competem no mercado também com ourives $^{8}$ autônomos e experientes, cujo aprendizado do ofício é passado de pai para filho e têm como principal serviço a confecção de peças artesanais sob demanda.

O designer empreendedor de joias por muitas vezes confecciona suas próprias peças, podendo ser em maior ou menor escala, a depender do processo produtivo escolhido: totalmente artesanal (ourivesaria) ou com auxílio de novas tecnologias (tridimensionais). Em alguns casos, o processo é misto, em parte terceirizado e em parte feito pelo designer. Um exemplo disto é quando o designer faz a modelagem manual em uma cera própria para joalheria e depois utiliza o protótipo para fazer a fundição terceirizada. Há ainda casos em que a confecção é totalmente terceirizada, porém sempre acompanhada de perto e orientada pelo designer, que consegue ter controle bastante rígido do resultado por possuir conhecimento técnico sobre o assunto.

Nesse sentido é possível traçar um paralelo entre esses perfis de designers empreendedores de joias e as linhas de pesquisa apontadas por Ferrara. $O$ designer de joias artesão ou ourives se aproxima do conceito de artesanato DIY, onde o custo para fabricação se torna mais baixo devido ao caráter artesanal, e onde o designer explora técnicas tradicionais de ourivesaria de forma a dar às joias uma estética própria, relacionada ao seu estilo como artista e criador. Embora normalmente preveja o uso de técnicas tradicionais, integra também experimentações de técnicas próprias desenvolvidas e comumente resulta em peças com estética bastante atual e por vezes com influências dos fluxos de moda.

Figura 1 - Confecção manual de joias utilizando técnicas de ourivesaria
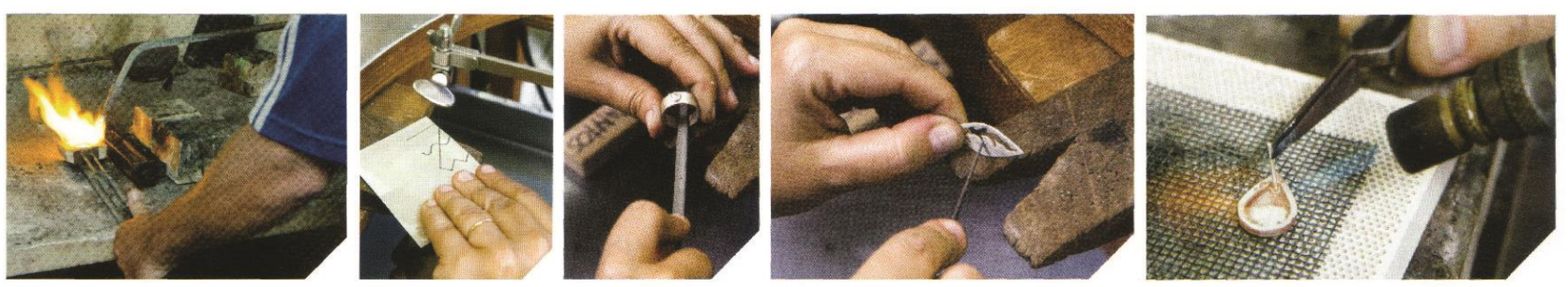

Fonte: SANTOS (2013)

\footnotetext{
${ }^{8}$ artesão/ artífice que confecciona peças em metais preciosos, como ouro e prata.
} 
Com o crescimento e propagação de tecnologias novas e, portanto, mais avançadas, sendo hoje principalmente as tecnologias de natureza digital, o equivalente ao artesanato tecnológico também aparece no design de joias. As tecnologias tridimensionais (3D) quando aplicadas na produção de joias, compreendem as etapas de modelagem digital e prototipagem rápida em resina para confecção de molde e posterior fundição. As etapas de prototipagem e fundição geralmente são terceirizadas. $O$ designer de joias empreendedor costuma entrar em um ou mais processos, dentre os mais comuns: criação e desenvolvimento, modelagem tridimensional e acabamento da peça, popularmente chamado de apuração. Há casos também em que somente a primeira etapa de criação pertence ao designer, mas sempre sob a orientação do conhecimento técnico do mesmo.

Figura 2 - À esquerda, modelagem tridimensional de joia: a partir do modelo virtual é possível prototipar um modelo em resina que pode ser usado para fundir peças em metal. À direita, modelo em resina impresso em 3D e molde bipartido em silicone.
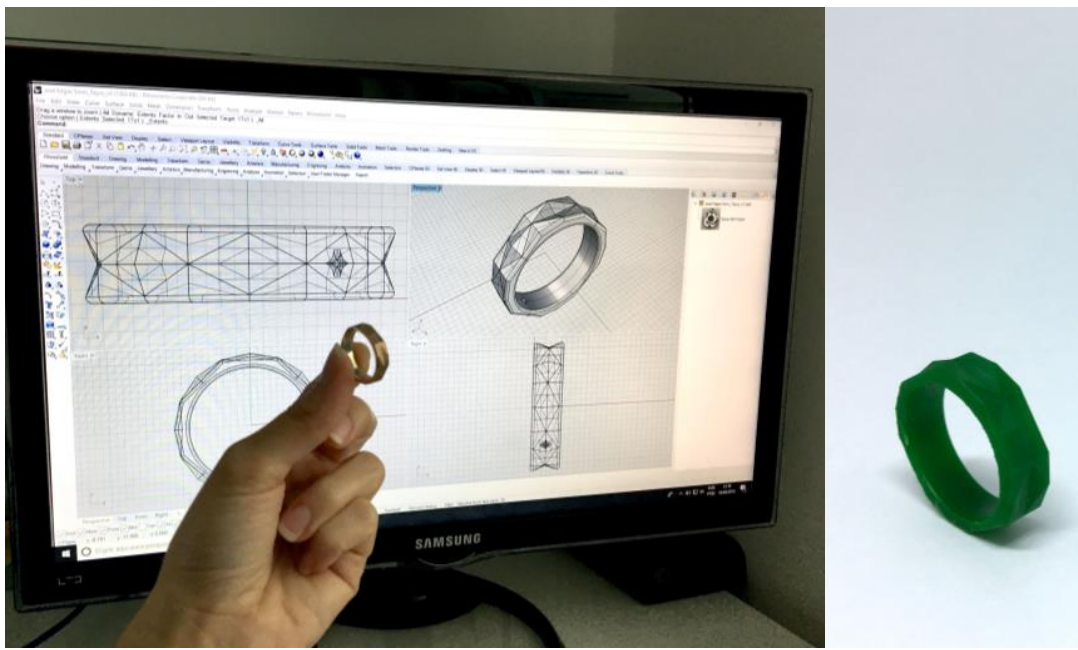

Fonte: o autor

Figura 3 - Modelagem manual de modelo em cera: técnica precedente ao aparecimento da prototipagem rápida; também permite a reprodução de peças através de fundição por cera perdida
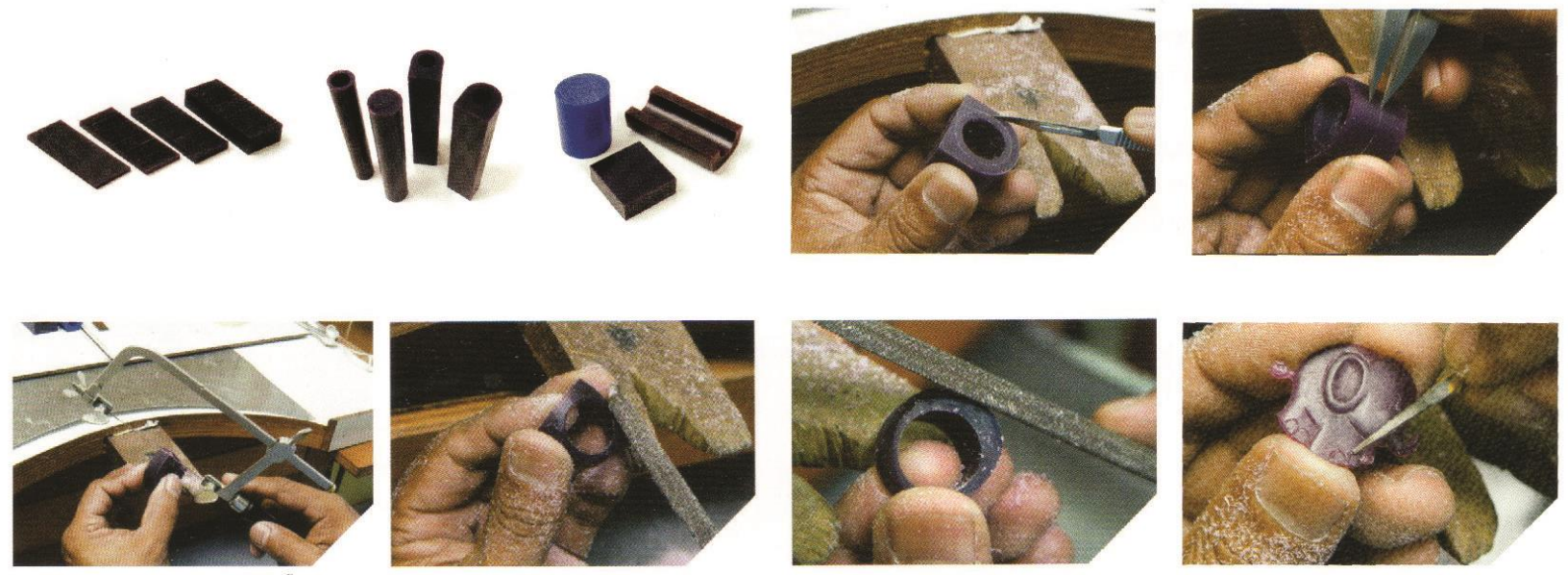

Fonte: SANTOS (2013) 
Já a categoria chamada de artesanato eletrônico, embora existente, ainda está em fase de amadurecimento no campo das joias. Isso se deve principalmente às restrições quanto ao processo produtivo de prototipagem 3D e os materiais nobres normalmente utilizados pela joalheria: prata e ouro. Embora já exista uma máquina que imprime peças diretamente em metais preciosos incluindo o ouro (da empresa Cooksongold, modelo PRECIOUS M 080), o preço de aquisição ainda é muito elevado e por isso é pouco utilizada pelo mercado.

Figura 4 - Joias em nylon (poliamida) produzidas por impressão 3D (SLS - sinterização a laser)

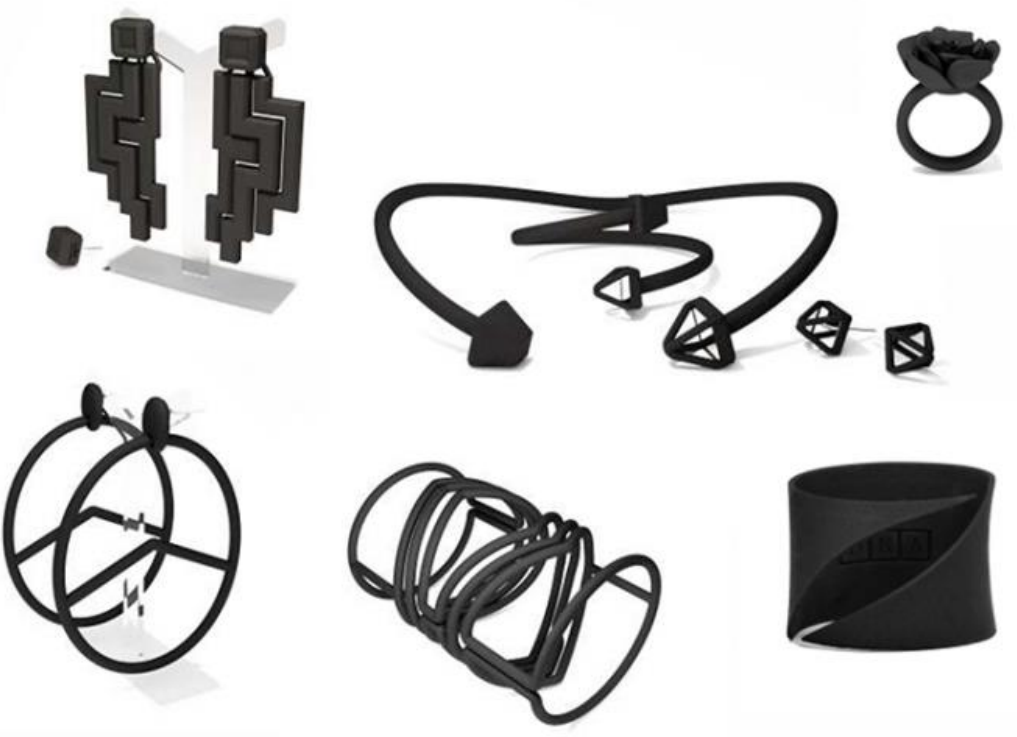

Fonte: o autor

As impressoras 3D mais amplamente difundidas no mercado tem como matéria-prima o plástico, como por exemplo, nylon (poliamida), ABS (acrylonitrile butadiene styrene) e PLA (poliácido láctico). Já existem hoje iniciativas onde o cliente compra a joia a partir de uma imagem renderizada ${ }^{9}$ exposta online. Porém nesse caso ou as peças são feitas em material plástico, ou elas passam pelo processo de confecção de molde (conforme explica figura 1) e por isso, não podem ser consideradas nesta categoria. Isso se deve ao seu processo produtivo misto que inclui tecnologias tridimensionais, fundição por cera perdida e apuração manual. Convém salientar que o uso de materiais não preciosos é comumente aceito pelo designer empreendedor, tendo como influência à crítica a preciosidade iniciada nos movimentos autorais anteriormente citados.

\footnotetext{
${ }^{9}$ do inglês to render, é uma função realizada por softwares 3D que realizam a conversão de um arquivo tridimensional para uma representação bidimensional, ou seja, uma imagem, e na maioria das vezes com características realísticas, como simulação de material, iluminação e sombras.
} 
Figura 5 - Processos da joalheria e as possibilidades de inserção do designer empreendedor

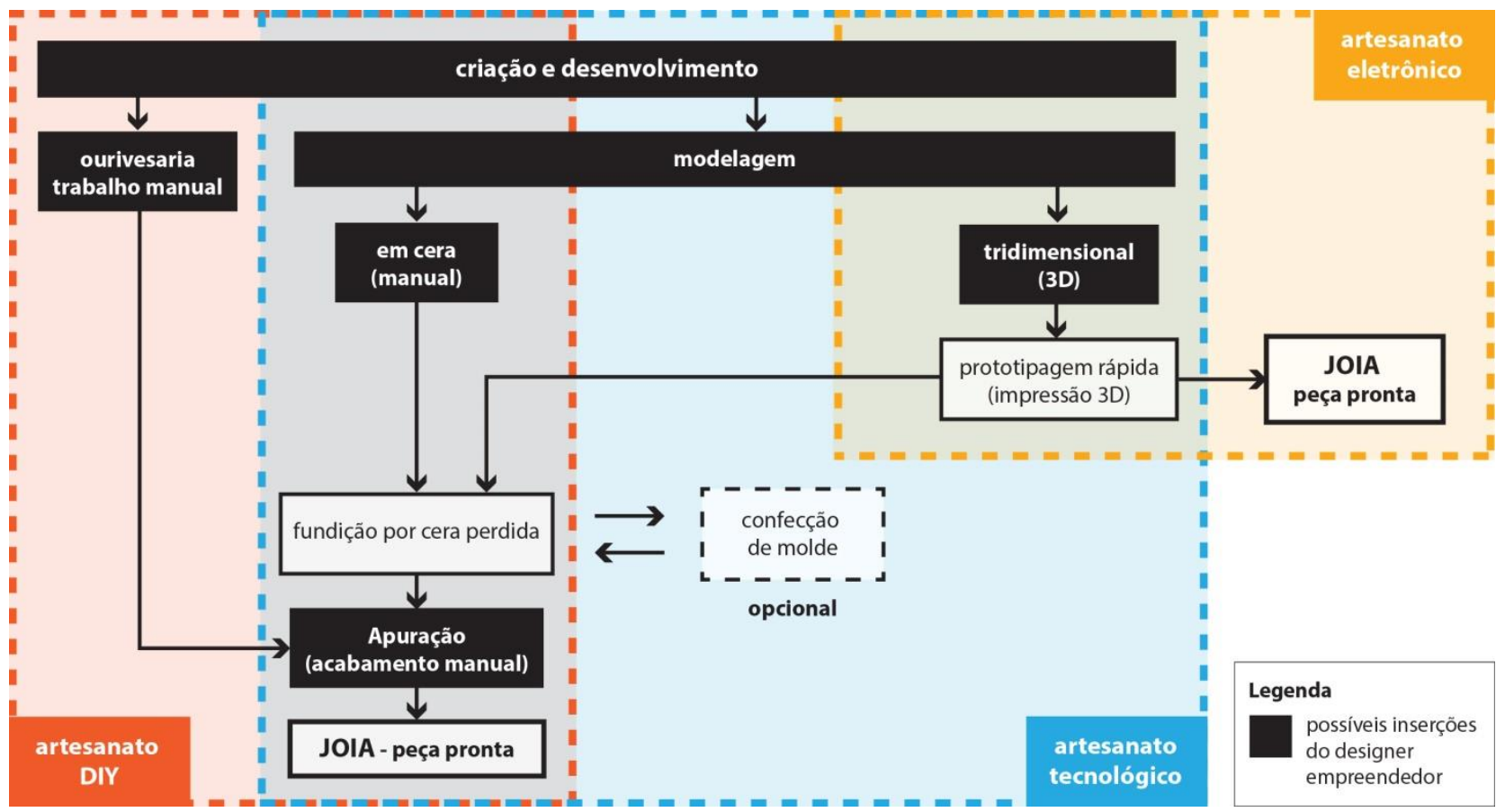

Fonte: o autor

As redes sociais (Facebook e Instagram) e os eventos locais como, por exemplo, feiras de moda, ajudam a impulsionar esses designers empreendedores. Através destas ferramentas de comunicação digital, o designer pode contar um pouco mais sobre seu processo produtivo e criativo. Cria-se uma aura de encantamento tanto com o processo manual e artesanal da joia, quanto com o conhecimento sobre o uso de tecnologias avançadas para fabricação das peças. Isso tudo é somado ao viés individual de estilo de cada designer enquanto criador de formas belas e bem pensadas.

Como reflexo deste crescimento no Brasil, podemos exemplificar uma iniciativa interessante: o surgimento no Rio de janeiro de um evento específico para exposição e venda de peças de designers e joalheiros autorais (e empreendedores). O evento, chamado "Joialerismo Expo" (sic) teve sua primeira edição em 2015 e acontece de uma a duas vezes por ano. Iniciou-se como uma ferramenta para fomentar a joalheria local fluminense e acabou atraindo também designers de outros estados brasileiros. $\mathrm{O}$ acesso direto do público ao joalheiro, que pode explicar cada detalhe de sua criação e de seu processo produtivo, sem intermediários, alimenta ainda mais essa valorização do trabalho autoral.

\subsection{Novas Tecnologias}

O aparecimento do designer empreendedor, além de influenciado pelo contexto da contemporaneidade, foi em grande parte impulsionado também pelo surgimento de novas tecnologias que permitem produções únicas ou em pequena escala. Para Harvey (1992), a recessão de 1973 evidenciou uma transição na economia capitalista do regime fordista para o regime de acumulação flexível. A crise se manifestou por uma falta de demanda efetiva por produtos frutos de produção em massa. Uma das consequências foi um maior ecletismo de práticas de trabalho e o surgimento de pequenos negócios, manufaturas domésticas, oficinas e 
trabalhos artesanais em geral. Ainda para o autor, uma das posições aceitas sobre essa flexibilidade é amplamente defendida por Piore e Sabel (apud Harvey, 1992, p.177), de que novas tecnologias tornam possíveis rearranjos nas relações de trabalho e nos sistemas de produção.

$\mathrm{Na}$ Joalheria, embora haja uma vertente de designers que possuem como foco o processo manual e artesanal da confecção da joia, não podemos ignorar a força das novas tecnologias, em especial as tecnologias tridimensionais e de manufatura digital, como ferramenta para dar autonomia ao designer empreendedor.

\section{A construção de uma relação mais contemporânea entre empreendimentos artesanais e o mercado vai precisar ir além do uso de novas tecnologias de produção e de comunicação. Ferramentas como o CAD, manufatura rápida, softwares de gestão e ITC são necessariamente parte das habilidades que qualquer artesão contemporâneo deve dominar, assim como a arte da negociação. ${ }^{10}$ (FERRARA, 2011, p.11)}

Além do aspecto produtivo, ainda em termos de autonomia, as tecnologias 3D trazem ganhos também na fase de projeto: permitem também ao designer definir, visualizar e analisar digitalmente a forma final da peça - podendo esta sofrer quantas alterações forem necessárias antes mesmo de realizar gastos com material e protótipo físico. Além disso, o próprio cliente pode ver a peça digitalmente e até mesmo solicitar as alterações de projeto antes da confecção.

Por outro lado, o uso intenso e/ou quase exclusivo de tecnologias tridimensionais traz perdas de conhecimentos e habilidades específicas da ourivesaria, que correm o risco de serem perdidas ou esquecidas por não serem mais passadas adiante. Perde-se o valor do trabalho artesanal e da dedicação do artesão. Além disso, os profissionais especializados, experientes e qualificados que antes atuavam como ourives, acabam perdendo espaço no mercado. Por estes e outros motivos, a inserção destas novas tecnologias na joalheria tem sido foco de discussão entre os profissionais e atores da indústria joalheira e deve ser vista com cautela. Atualmente é possível encontrar no Rio de Janeiro inúmeros cursos de ourivesaria, muito procurados por designers que querem empreender, e que acabam por auxiliar na disseminação desse conhecimento de confecção manual e ajudam a manter viva a tradição da joia feita à mão.

Ainda hoje a indústria joalheira e as grandes marcas, assim como toda indústria do luxo, se baseiam principalmente na perpetuação das técnicas tradicionais e nas habilidades artesanais na fabricação de produtos, como forma de criar um lugar de memória que legitime a tradição da marca. Isso faz parte da estratégia de conservação dos detentores da posição dominante, conforme explica Bordieu (1974), que tem por objetivo obter lucro do capital progressivamente acumulado. Ainda por esta lógica, é compreensível que os chamados novos entrantes, incluindo os novos designers empreendedores, usem uma estratégia de subversão, ao propor uma inversão radical de valores a partir do uso de tecnologias tridimensionais e da produção por meio de manufaturas digitais.

Atualmente algumas marcas já fazem uso dessa estratégia, que tem grade potencial de crescimento nos próximos anos, conforme as tecnologias forem se tornando ainda mais acessíveis. A empresa alemã Stilnest, por exemplo, explica em seu site o processo produtivo detalhadamente,

\footnotetext{
${ }^{10}$ tradução livre de: The construction of a more contemporary relationship between craft enterprises and the market will need to go through the use of the new production and communication technologies. Tools such as CAD, rapid manufacturing technologies, management software and ITC are necessarily part of the skills that any contemporary craftsman must master, just like the art of the own trade.
} 
informando para o consumidor sobre o uso de tecnologias 3D e usa deste artifício para se diferenciar no mercado. Já empresa brasileira Poésie (Campo Grande - MS), utiliza-se da modelagem tridimensional e imagens renderizadas para vender anéis de noivado e de casamento sob demanda diretamente pelo site. A empresa americana de Boston JEWELv vai mais além, e usa os mesmo recursos para vender joias personalizadas, que podem ser modificadas e criadas diretamente pelo cliente no site, a partir de predefinições de acabamentos e gemas. A marca brasileira Noiga (Curitiba - PR), utiliza a impressão 3D diretamente em nylon (tecnologia de sinterização a laser - SLS) para fabricar os acessórios de suas coleções (figura 4).

\section{Conclusão}

Estamos em um momento histórico e cultural onde as responsabilidades para o sucesso de vida foram totalmente transferidas para o indivíduo, e por isso, cabe a este tomar medidas para se qualificar e atuar no mercado de forma a garantir seu sustento, sem contar com o apoio de nenhuma instituição específica. A insegurança constante e a crise do trabalho geraram uma resposta proativa de parte dos designers, que viram no empreendedorismo uma alternativa para manter seu sustento dentro deste cenário dinâmico.

O luxo e, consequentemente, também a joalheria encontram-se em um momento de desafios e de reestruturação a partir do contexto contemporâneo. Embora estejamos vivendo em uma sociedade de consumidores, esta compra se dá de uma maneira mais complexa do que em períodos anteriores, e com muitos elementos de valor simbólico. Estes indivíduos estão sedentos por satisfazer seus desejos regularmente e construir diferentes e novas identidades de si próprio a todo o momento, de maneira volátil e mutável como a moda. Buscam no luxo a necessidade de se sentirem mais seguros consigo mesmo e com o mundo, mesmo que temporariamente, como única alternativa viável para sobreviver a sua única certeza: a instabilidade.

Os designers de joias autônomos também envolvidos pela instabilidade dos tempos contemporâneos, e na busca por tomar as rédeas de seu sucesso, perceberam oportunidades em conjugar suas habilidades estratégicas com o empreendedorismo. Eles têm agora em suas mãos ferramentas que permitem acompanhar as dinâmicas mudanças de mercado, com rapidez e maior controle do resultado final. Os avanços da tecnologia deram aos designers um impulso extra para sua autonomia produtiva, e conforme a evolução exponencial da manufatura digital, a tendência é que o crescimento desta atividade possa a vir alcançar um crescimento proporcional. Por fim, a valorização do trabalho autoral pelo mercado consumidor, dá aos designers empreendedores de joias novas condições para realizar seus trabalhos incessantes de ponta a ponta do processo, e combustível para seguir produzindo de maneira independente, e alimentando as mutáveis identidades do indivíduo contemporâneo.

\section{Referências}

BAUMAN, Zygmunt. Modernidade Líquida. Rio de Janeiro: Jorge Zahar Editora, 2001.

BOURDIEU, Pierre. Alta costura e Alta Cultura. Comunicação feita em Noroit (Arras) em novembro de 1974 e publicada em Noroit, 192, novembro de 1974, dezembro de 1974, janeiro de 1975.

Cooksongold. Disponível em: <http://www.cooksongold-emanufacturing.com/> Acesso em 23 de janeiro de 2018.

DAYÉ, Claudia; CORNEJO, Carlos; COSTA, Gracia. Joalheria no Brasil: história, mercado e ofício. 
Barueri: DISAL, 2017.

FERRARA, Marinella. Design and self-production. The advanced dimension of handcraft. Strategic Design Research Journal, volume 4, p. 5-13, Jan-Abr 2011.

HALL, Stuart. A identidade cultural na pós-modernidade. Rio de Janeiro: DP\&A, 2006.

HARVEY, David. Condição Pós-Moderna: Uma Pesquisa sobre as Origens da Mudança Cultural. São Paulo: Edições Loyola, 1992.

JEWELv. Homepage institucional.Disponível em: <https://jewelv-3.myshopify.com/> Acesso em 23 de janeiro de 2018.

Joialerismo Expo. Homepage institucional. Disponível em: <https://www.joialerismoexpo.com/>. Acesso em 23 de janeiro de 2018.

LIPOVETSKY, Gilles; ROUX, Elyette. O luxo eterno: da idade do sagrado ao tempo das marcas. São Paulo: Companhia das Letras, 2005.

MERCALDI, Marlon Aparecido. Joia contemporânea: relações entre o adorno e o corpo. 150f. Dissertação (Mestrado) - Universidade Estadual Paulista "Júlio de Mesquita". Faculdade de Arquitetura, Artes e Comunicação, Bauru, 2016.

Noiga. Homepage institucional. Disponível em: <http://www.noiga.com.br/> Acesso em 23 de janeiro de 2018.

Poésie. Homepage institucional. Disponível em: <https://www.poesie.com.br/> Acesso em 23 de janeiro de 2018.

SANTOS, Rita. Joias: fundamentos, processos e técnicas. Rio de Janeiro: Senac Nacional, 2013.

Stilnest. Homepage institucional. Disponível em: < https://stilnest.com/en_int/> Acesso em 23 de janeiro de 2018. 